\title{
Spin-state studies with XES and RIXS: From static to ultrafast
}

Vankó, György ; Bordage, Amélie ; Glatzel, Pieter ; Gallo, Erik ; Rovezzi, Mauro ; Gawelda, Wojciech ; Galler, Andreas ; Bressler, Christian ; Doumy, Gilles ; March, Anne Marie

Total number of authors:

22

Published in:

Journal of Electron Spectroscopy and Related Phenomena

Link to article, DOI:

10.1016/j.elspec.2012.09.012

Publication date:

2013

Document Version

Early version, also known as pre-print

Link back to DTU Orbit

Citation (APA):

Vankó, G., Bordage, A., Glatzel, P., Gallo, E., Rovezzi, M., Gawelda, W., Galler, A., Bressler, C., Doumy, G., March, A. M., Kanter, E. P., Young, L., Southworth, S. H., Canton, S. E., Uhlig, J., Smolentsev, G., Sundström, V., Haldrup, K., Brandt van Driel, T., ... Lemke, H. T. (2013). Spin-state studies with XES and RIXS: From static to ultrafast. Journal of Electron Spectroscopy and Related Phenomena, 188, 166-171.

https://doi.org/10.1016/j.elspec.2012.09.012

\section{General rights}

Copyright and moral rights for the publications made accessible in the public portal are retained by the authors and/or other copyright owners and it is a condition of accessing publications that users recognise and abide by the legal requirements associated with these rights.

- Users may download and print one copy of any publication from the public portal for the purpose of private study or research.

- You may not further distribute the material or use it for any profit-making activity or commercial gain

- You may freely distribute the URL identifying the publication in the public portal 


\title{
Spin-state studies with XES and RIXS: From static to ultrafast
}

\author{
György Vankó, Amélie Bordage \\ Wigner Research Centre for Physics, Hungarian Academy Sciences, H-1525 Budapest, P.O.B. 49., Hungary \\ Pieter Glatzel, Erik Gallo, Mauro Rovezzi \\ European Synchrotron Radiation Facility (ESRF), 6 Rue Jules Horowitz, BP220, 38043 Grenoble Cedex 9, France
}

Wojciech Gawelda, Andreas Galler, Christian Bressler

European XFEL, Albert-Einstein Ring 19, D-22 761 Hamburg, Germany

Gilles Doumy, Anne Marie March, Elliot P. Kanter, Linda Young, Stephen H. Southworth

X-ray Science Division, Advanced Photon Source, Argonne National Laboratory, 9700 S. Cass Ave., Argonne, Illinois 60439, $U S A$

Sophie Canton, Jens Uhlig, Villy Sundström

Dept. of Chemical Physics, Lund University, Box 124;MAX-lab, Lund University, Box 118, 22100 Lund, Sweden

Kristoffer Haldrup, Tim Brandt van Driel, Kasper S. Kjaer, Henrik T. Lemke, Martin M. Nielsen

Centre for Molecular Movies, Univ. Copenhagen, Niels Bohr Inst, DK-2100 Copenhagen, Denmark

\begin{abstract}
We report on extending hard X-ray emission spectroscopy (XES) together with resonant inelastic X-ray scattering (RIXS) to study ultrafast phenomena in a pump-probe scheme at $\mathrm{MHz}$ repetition rates. The investigated system consists of low-spin (LS) $\mathrm{Fe}^{\mathrm{II}}$ complex compounds, where optical pulses induce a spinstate transition to their $\approx$ nanosecond-lived high-spin (HS) state. Time-resolved XES clearly reflects the spinstate variations with very high signal-to-noise ratio, in agreement with HS-LS difference spectra measured via thermally induced spin crossover, and reference HS-LS systems in static experiments. 1s2p RIXS, measured at the Fe 1s pre-edge region shows variations after laser excitation, which are consistent with the formation of the HS state. Our results demonstrate that now X-ray spectroscopy experiments with overall rather weak signals, such as RIXS, can be reliably exploited to study chemical and physical transformations on ultrafast time scales.
\end{abstract}

Keywords: molecular switching, time-resolved spectroscopy, X-ray spectroscopy, spin transition, photoinduced transition, ultrafast phenomena, pump-probe experiments

\section{Introduction}

The spin state of transition metal ions affects the properties of their compounds both on macroscopic 
and microscopic levels, as it has a large influence on ionic and thus molecular size, lattice unit cell volume, density, transport, magnetic and vibrational properties. Particularly interesting are cases when the spin state can be changed by external stimuli, with implications in atomic, molecular and solid state physics, geophysics, chemistry, and biochemistry. Molecular systems that can be switched between their different spin states are especially intriguing for their potential applications in high-density molecular storage devices, and the photochemical properties may prove to become useful in novel light energy converters based on Fe-containing molecules. At low temperatures many low-spin (LS) $\mathrm{Fe}^{\mathrm{II}}$ complex compounds can be switched by light to a high-spin (HS) state [1, 2]; however, the detailed mechanism of the LS to HS switching process is still under debate [3]. Tools sensitive to the electronic structure and the spin state, which can also be utilized on the femtosecond (fs) to nanosecond (ns) time scales, can shed light on the yet unknown details of the relevant intermediate steps involved in the spin-state switching process. Previously, fs laser spectroscopy has been used for this purpose, which have delivered a rich picture of the ultrafast events taking place on the first few hundred fs $[4,5,6,7,8]$. These tools are, however, rather insensitive to the changes in the spin state next to the concomitant geometric structure changes.

Hard X-ray spectroscopies can provide unique insights into the electronic and geometric structure, combined with element-, orbital-, and orientation sensitivity $[9,10,11]$. These techniques probe the bulk properties of the sample, and are even compatible with extreme conditions due to the large penetration depths [12]. X-ray Absorption Spectroscopy (XAS) with its variants X-ray Absorption Near Edge Structure (XANES) and Extended X-ray Absorption Fine Structure (EXAFS) have proven their utility in determining the unoccupied electron states and the local structure, respectively $[13,14,15,16]$. X-ray Emission Spectroscopy (XES) and Resonant Inelastic X-ray Scattering (RIXS) are very powerful in elucidating the electronic structure, providing information on the electron energies, local geometry, spin and valence state, etc. $[9,17,18,19,20,21,22,23]$. These tools can thus deliver complementary information to the usually employed ultrafast laser spectroscopies, when implemented in a pump-probe experiment with a laser pump and a time-delayed X-ray probe pulse.

The wide-spread extension of hard X-ray techniques to the ultrafast time domain has been initiated at synchrotron radiation sources about a decade ago, and has remained limited in its time resolution to ca. 50-100 ps, due to the intrinsic X-ray pulse width in this range. In nearly all these cases, such studies on molecular systems have employed X-ray absorption spectroscopy $[24,25,26]$ or X-ray scattering (XRS) techniques $[25,27,28,29,30,31,32]$ only and have been, with few exceptions, limited to low repetition rates (ca. $1 \mathrm{kHz}$ ) by using Ti:sapphirebased amplified laser systems, which deliver a sufficient number of optical photons to match the number of ground state molecules in the laser beam [24]. In this way, the photoexcitation of a sufficient fraction of the sample (5-50\%) was ensured for each laser pulse. This was necessary, since the number of probing Xray photons/pulse are orders of magnitude lower (and their $\mathrm{MHz}$ rate cannot be exploited), which so far hampered a wide-spread use of such structural Xray techniques. More flux demanding experiments, such as X-ray emission spectroscopy (XES) or even the very low cross section inelastic X-ray scattering techniques (IXS), thus become nearly impossible to envision. However, a recent pioneering experiment successfully recorded transient XES spectra on photoexcited aqueous $\left[\mathrm{Fe}(\text { bipy })_{3}\right]^{2+}$ at the $\mathrm{Fe} \mathrm{K} \alpha$ emission line, which reflected a line shape variation characteristic for the LS to HS transition [33].

The above works also showed that the integrated number of X-ray photons is the bottleneck for these time-resolved X-ray techniques, and in consequence we have developed a setup employing a high-power $\mathrm{MHz}$ laser, which allows for a substantial increase in detection efficiency due to a closer match between the repetition rates of both the synchrotron and the laser source. This strategy now permits ca. $10^{12} \mathrm{X}$ ray photons per data point to be collected in a few seconds, which is at least 3 (4?) orders of magnitude larger than with conventional $\mathrm{kHz}$ laser systems after extensive data acquisition times of several days. With this approach one can now envision to employ multiple X-ray structural tools simultaneously on the 
sample during the course of a light-triggered chemical reaction or physical transition.

\section{Experimental methods}

We have extended the capabilities of such laserX-ray studies towards $\mathrm{MHz}$ pump-probe repetition rates, both at ID26 of the European synchrotron radiation facility (ESRF) and at sector 7-ID of the Advanced Photon source (APS). These high-energy synchrotron radiation sources offer the advantage to tailor the laser pump rate to that of all electron bunches within the storage ring, so that one can perform such studies with quasi-static S/N.

Both beamlines use undulator radiation, which is then monochromatized using a double crystal monochromator equipped with either diamond (APS) or silicon (ESRF) crystals. At 7-ID beamline, the Xrays are then focussed down to $5 \mu \mathrm{m}$ FWHM spot size at the sample by Kirkpatrick-Baez mirrors [34], whereas at ID26 the beam size is tailored using a toroidal (?) mirror and further downstream slit system to a spot of $100 \times 500 \mu \mathrm{m}^{2}$. Time-resolved experiments are most conveniently performed at both synchrotrons in special equidistant bunch filling modes, namely in the 24-bunch (APS) and 16-bunch modes (ESRF). In the 24-bunch mode at a ring current of $102 \mathrm{~mA}$ and for the X-ray energies between $7.5 \mathrm{keV}$ and $8.2 \mathrm{keV}$, the X-ray incident flux on 7-ID is ca. $2 \times 10^{5}$ photons that are delivered to the sample in the $\sim 80$ ps FWHM X-ray pulse at a repetition rate of 6.52 MHz. In 16-bunch mode (90 mA, 5.68 MHz), $\approx 2 \times 10^{6}$ photons are delivered to the sample in $\sim 100$ ps FWHM for each X-ray pulse on ID26.

Aqueous solution of $\left[\mathrm{Fe}(\text { bipy })_{3}\right]^{2+}$ (with concentrations between $12 \mathrm{mM}$ and $25 \mathrm{mM}$ ) in form of a $100 \mu \mathrm{m}$ thick sheet from a liquid jet was used as sample in both experiments. From the APS experiment, we also report here time-resolved $1 \mathrm{~s} 2 \mathrm{p}$ RIXS taken on a $20 \mathrm{mM}$ solution of $\left[\mathrm{Fe}(\text { terpy })_{2}\right]^{2+}$ (terpy:2,2':6',2"terpyridine). The laser installed in the APS 7-ID$\mathrm{D}$ hutch [35] was operated at a $3.26 \mathrm{MHz}$ repetition rate, emitting $532 \mathrm{~nm}$ radiation with $5 \mathrm{~W}$ power corresponding to pulse energies of $2 \mu \mathrm{J}$; the pulse width was $10 \mathrm{ps}$, and was focussed to a $25 \mu \mathrm{m}$ FWHM spot size on the sample. Spatial and temporal stability were $5 \mu \mathrm{m}$ and 10 ps over several hours [35]. At ID26, we used a mobile fs laser system described by the following parameters: wavelength $515 \mathrm{~nm}$, repetition rate $1.42 \mathrm{MHz}$, pulse length $280 \mathrm{fs}$. Cylindrical lenses were used to achieve an elliptical beam profile of ca. $125 \times 600 \mu \mathrm{m}^{2}$, which provided a good overlap with the X-ray spot size on the sample.

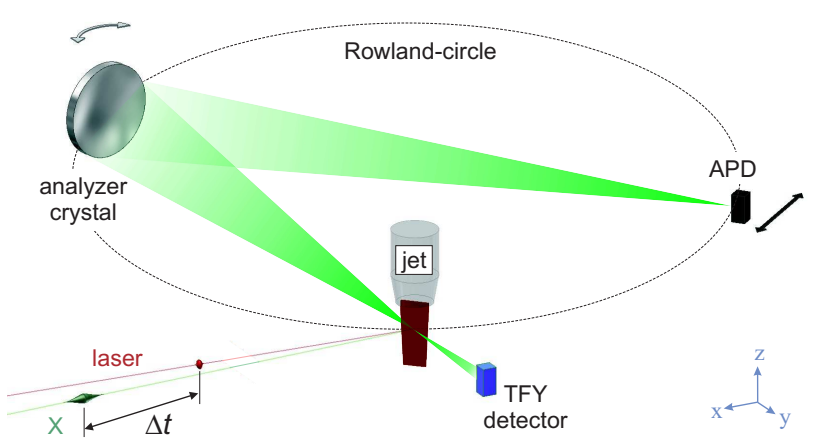

Figure 1: Schematic setup at APS 7-ID; see the text for details.

Figure 1 shows the schematic experimental setup. The laser and X-ray beams impinge almost collinearly (5 degrees angle of separation) on a fast-flowing 100 $\mu \mathrm{m}$ thick liquid jet mounted at $45^{0}$ to the beam propagation direction. A wavelength-dispersive crystal spectrometer was constructed at 7-ID (in the horizontal plane) to measure the XES signal using a spherically bent analyzer crystal of $10 \mathrm{~cm}$ diameter positioned at a $90^{\circ}$ scattering angle, and an avalanche photodiode (APD) detector at its focus, such that the sample-analyzer-detector setup constitutes a $1 \mathrm{~m}$ Rowland circle. At ID26, the permanent five-crystal spectrometer of the beamline, built in the vertical plane, was used. A thin plastic bag filled with $\mathrm{He}$ was installed inside both spectrometers to minimize absorption loss of the XES intensity. The spectra of the emitted X-rays were recorded by scanning the Ge(440) spherically bent analyzer crystal through the appropriate Bragg angle range to collect the Fe $\mathrm{K} \alpha$ spectra, and the APD was moved accordingly. Total energy resolution measured through the spectrometer on 7-ID (resp. ID26) was $1.0 \mathrm{eV} \mathrm{FWHM}$ at $6404 \mathrm{eV}$ (resp. ???? at ????? eV), a resolution composed of $0.4 \mathrm{eV}$ (resp. ??? eV) and $0.9 \mathrm{eV}$ (resp. 
???? eV) contributions from the monochromator and the spectrometer, respectively.

The relative timing between the laser and $\mathrm{X}$ ray pulses is controlled with an electronic phase shifter and it allows choosing a particular time delay $\Delta t$, at which we recorded XES spectra or RIXS planes. We used a data acquisition scheme where two spectra are collected alternately, following the laser $\mathrm{ON} / \mathrm{OFF}$ pattern (at APS every second X-ray pulse was pumped with the laser, whereas at ESRF every 4th X-ray pulse), to acquire data on the ground and laser-excited states. This permitted us to optimally exploit the incident X-ray flux by matching the repetition rates of both pump and probe sources, similarly to our previously employed strategy with $\mathrm{kHz}$ systems $[7,36]$.

\section{Results and discussion}

\subsection{The high-spin state of $\left[\mathrm{Fe}(\text { bipy })_{3}\right]^{2+}$ as reflected by XES}

In an X-ray absorption study, Gawelda et al. determined the structure of the light-induced $\approx 0.6 \mathrm{~ns}-$ lived excited state of $\left[\mathrm{Fe}(\text { bipy })_{3}\right]^{2+}$ and showed that the structural variations correspond to a $0.2 \AA$ elongation of the $\mathrm{Fe}-\mathrm{N}$ bond length [8], typical for a LS to $\mathrm{HS}$ transition in $\mathrm{Fe}^{2+}$ systems [37]. In our recent extension towards ps time-resolved XES (using a low-repetition pump laser at $1 \mathrm{kHz}$ ), we characterized the spin momentum change of the $\mathrm{Fe}^{\mathrm{II}}$, which was in a good agreement with the expected $\Delta S=2$ [33]. In the experiments reported here, the $\mathrm{MHz}$ pump-probe rates have allowed us to collect very high quality data at acquisition times similar to conventional static experiments. Figure 2 displays the transient $K \alpha$ signals obtained on the aqueous solution of the $\left[\mathrm{Fe}(\text { bipy })_{3}\right]^{2+}$ molecules, with additional HSLS reference spectra. The latter includes the theoretical difference spectrum using the charge transfer multiplet approach (Fig. 2c), as well as difference in static experiments: the difference of the room temperature $\mathrm{K} \alpha$ spectra of HS $\left[\mathrm{Fe}(\text { phen })_{2}(\mathrm{NCS})_{2}\right]$ and LS $\left[\mathrm{Fe}(\text { bipy })_{3}\right]^{2+}$ (Fig. 2d), and the difference measured at thermal spin crossover in $\left[\mathrm{Fe}(\text { phen })_{2}(\mathrm{NCS})_{2}\right]$, well above and below the transition temperature (Fig. 2e).

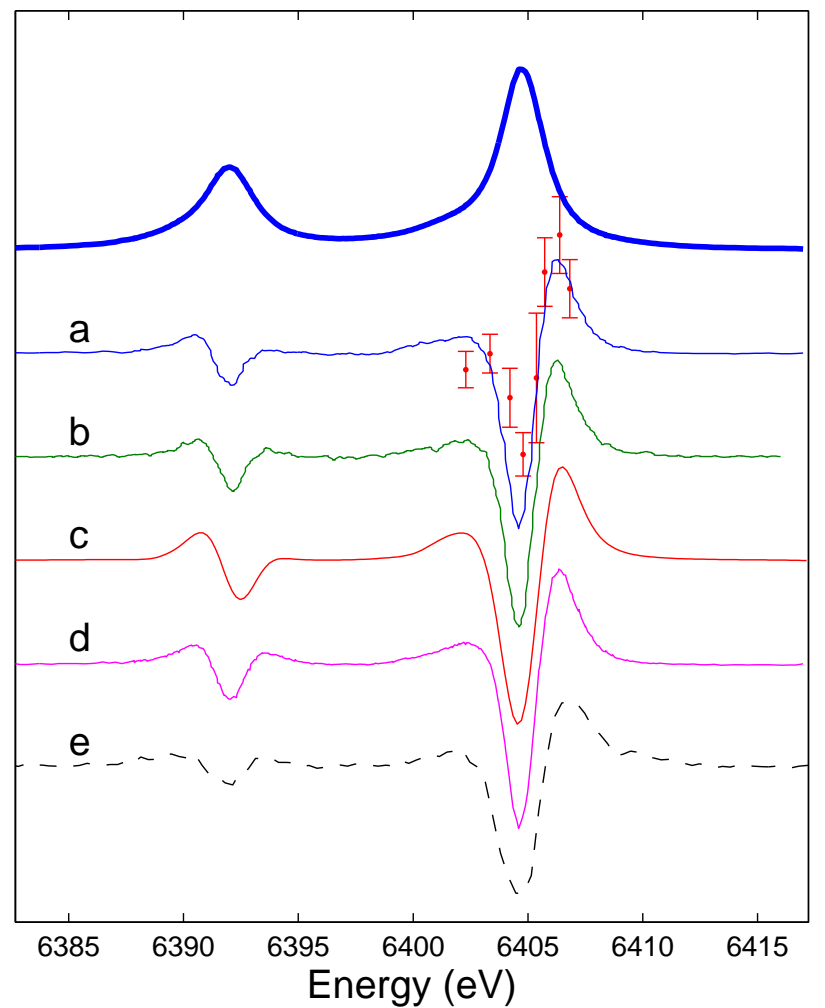

Figure 2: $\mathrm{K} \alpha$ spectra of the aqueous solution of (LS) $\left[\mathrm{Fe} \text { (bipy) }{ }_{3}\right]^{2+}$ (top thick blue curve, scaled down) and several HS-LS difference spectra. a: $\left[\mathrm{Fe}(\mathrm{bipy})_{3}\right]^{2+}$ laser on - laser off transient from APS 7-ID (taken at a time delay of $\Delta t=80 \mathrm{ps}$ ); the circles with error bars show our previous $\mathrm{kHz}$ experiment at the SLS[33] for comparison. b: $\left[\mathrm{Fe}(\text { bipy })_{3}\right]^{2+}$ transient spectrum from ESRF ID26 $(\Delta t=77 \mathrm{ps})$. c: Difference curve of the $\mathrm{K} \alpha$ spectra calculated with the charge transfer multiplet approach for HS and LS Fe ${ }^{2+}$ in $\mathrm{O}_{\mathrm{h}}$ symmetry, from Ref. [33]. d: difference of the room temperature $\mathrm{K} \alpha$ spectra of the HS $\left[\mathrm{Fe}(\text { phen })_{2}(\mathrm{NCS})_{2}\right]$ and the LS $\left[\mathrm{Fe}(\text { bipy })_{3}\right]^{2+}$. e: static experiment at the thermal spin crossover of $\left[\mathrm{Fe}(\text { phen })_{2}(\mathrm{NCS})_{2}\right]$, the difference of the $\mathrm{K} \alpha$ spectra taken at the room temperature (HS form) and at $80 \mathrm{~K}$ (LS form) is shown.

The excellent agreement between the time-resolved and the static experiments, as well as with the theory, demonstrates that XES can reliably determine the $3 \mathrm{~d}$ spin momentum (or, more precisely, the number of unpaired electrons), and can be used as a powerful tool for ultrafast studies. 


\subsection{Time-resolved XES: Validation of the methodol- ogy for line shape analysis}

In conventional XES experiments aiming at the determination of the spin state, energy shifts and even line shape distortions can hinder the quantitative analysis. This is particularly true for a horizontal spectrometer arrangement, when avoiding these effects would require keeping the sample in the same position along the X-ray beam very precisely. In the same way, in cryostats, pressure cells, etc., it is often difficult to ensure that the sample remains in the same position when the temperature or the pressure is changed. Therefore, in many previous experiments the spectra were aligned on the main peak [38, 39, 40]. In order to circumvent this problem, in Ref. [18] we suggested aligning the spectra on their center of mass for cases when energy shifts can take place. A further typical assumption at the line shape analysis is that the fluorescence yield is not affected by the transition, so the XES intensity at a fluorescence feature is identical for both states; however, it is known that the $\mathrm{K} \beta: \mathrm{K} \alpha$ intensity ratio can show some chemical dependence [41]. Since the IAD approach is used more and more widely $[18,42,43,44,45,46]$, it is important to test the validity of these assumptions.

The alternating acquisition scheme of the present pump-probe experiment provides us with a unique opportunity to do so, since the two spectra are taken quasi-simultaneously. Therefore the sample position, the geometrical arrangement and all other parameters are identical for the two spectra in the laser ON/OFF (or pumped/unpumped) channels, that probe the LS ground state and the (partly) HS excited state, respectively. For $\left[\mathrm{Fe}(\text { bipy })_{3}\right]^{2+}$, the $\mathrm{K} \alpha$ spectra were of excellent statistical quality: 20 pairs of laser ON/OFF scans, with a total of $39 \times 10^{6}$ counts were taken, in two sets. We compare the difference of their center of mass $(\triangle \mathrm{COM}=\mathrm{COM}(\mathrm{HS})$ $\mathrm{COM}(\mathrm{LS})$ ) values, as well as the possible intensity variation for the laser $\mathrm{ON} / \mathrm{OFF}$ channels, with the ON values scaled to $100 \%$ conversion.

For the two sets, taken at average step size of 125 $\mathrm{meV}$ and $280 \mathrm{meV}, \Delta \mathrm{COM}$ values of $-5( \pm 22) \mathrm{meV}$ and $4( \pm 18) \mathrm{meV}$ were determined. However, the $\triangle \mathrm{COM}$ values of the individual scans scattered between \pm 1 step size. Moreover, 1-2 orders of magni- tude smaller errors are expected from counting statistics with error propagation, suggesting that the spectra are affected by some small instabilities during the pump-probe experiment. Nevertheless, the COM seems unperturbed and thus can be used for aligning the spectra at line shape analysis. In fact, the $\mathrm{K} \alpha$ difference spectrum of $\left[\mathrm{Fe}(\text { phen })_{2}(\mathrm{NCS})_{2}\right]$ is only similar to the others because the HS and LS spectra (taken from Ref. [18]) were now shifted to the same COM before making the difference. The such-treated spectrum displays a good similarity with the others, only it is broader due to the large beam size used in that previous experiment.

The differences of integrated intensity in the laser $\mathrm{ON}$ - normalized to the X-ray beam intensity monitor, and scaled to $100 \%$ HS conversion - and laser OFF channels is $\Delta I=-0.4 \pm 0.3 \%$, when compared to the laser OFF channel, for the first set of scans, and it is $-1.6 \% \pm 0.9 \%$ for the other. In certain scans evident crosstalk between the two channels were observed affecting a not more than one data point; however, a smaller electronics problem of this kind might have gone unnoticed. The scans on the $\left[\mathrm{Fe}(\text { terpy })_{2}\right]^{2+}$ result in $\Delta I=-0.9 \pm 0.3 \%$, all these indicate a small $\mathrm{K} \alpha$ yield loss of around $-0.7 \% \pm 0.2$ $\%$ at $100 \%$ HS conversion. In the same experiment, we also measured the $\mathrm{K} \beta$ spectra of the laser excited $\left[\mathrm{Fe}(\mathrm{bipy})_{3}\right]^{2+}$, and an effect of $\Delta I=+0.5 \pm 0.4 \%$ was observed (scaled to $100 \%$ spin conversion). We do not wish to conclude here on the possible effect on the electronic structure; however, we can claim that these small possible intensity variations will not undermine the accuracy of the spin-state determination.

\subsection{Time-resolved RIXS at the spin-state transition}

Resonant inelastic X-ray scattering (RIXS) can also gives valuable insights into the electronic structure $[10,9,11]$. For spin-state transitions the variations of the $3 \mathrm{~d}$ state energies and populations are substantial. Consequently, the RIXS planes taken at the 1s pre-edge resonances, which (at least partly) stem from $1 \mathrm{~s} \rightarrow 3 \mathrm{~d}$ transitions, are expected to show large variations at spin state changes. This has been demonstrated for the thermal SCO in $\left[\mathrm{Fe}(\text { phen })_{2}(\mathrm{NCS})_{2}\right]$ in a static experiment, again well below and above the transition temperature [18]. We 
replot these figures in Fig. 3, revealing that while for the LS case there is a single resonance, there are three of them for the HS state (ignoring splittings from the weak S-O interaction for the $3 \mathrm{~d}$ electrons). These resonances, while they are less accessible in XANES due to the lifetime broadening and the overlap of the peaks, clearly show up in the RIXS planes. Their difference is also shown; however, this old set of spectra are again of limited resolution, and a 2D splining was necessary to produce the difference. Nevertheless, it should be sufficient to lay down the topological expectations on what we should expect for a time-resolved difference spectrum for a $\mathrm{Fe}^{\mathrm{II}}$ spinstate transition. The lower row of Fig. 3 presents the 1s2p RIXS data for the light-induced spin-state transition in $\left[\mathrm{Fe}(\text { terpy })_{2}\right]^{2+}$ taken at 7 -ID. The changes of the affected $3 \mathrm{~d}$ states are quite clear from this figure: the intensity of the single peak of the ground state drops, and two additional peaks appear, indicating a more complex electron configuration following laser excitation (HS population was determined to $40 \%$ here). The difference spectra and the HS state spectrum reveal a structure with 3 resonances. This finding agrees very well with what is expected to be observed for the quadrupolar 1s3d resonances at $\mathrm{LS} \rightarrow \mathrm{HS}$ transition in an octahedral Fe(II) complex, and is in good agreement with what was observed for the pseudooctahedral $\left[\mathrm{Fe}(\text { phen })_{2}(\mathrm{NCS})_{2}\right]$ in static measurements at a thermal spin-state transition $[18,47]$. One should keep in mind, however, that the $\left[\mathrm{Fe}(\text { terpy })_{2}\right]^{2+}$ has a pronounced distortion from the $O_{h}$ symmetry, and lacks an inversion center; therefore, mixing of $3 \mathrm{~d}$ and $4 \mathrm{p}$ states is expected, and a relevant dipole contribution to the pre-edge might appear. Therefore, the complete understanding of the spectra requires an elaborate theoretical analysis, which is beyond the scope of the present paper.

\section{Conclusions}

We presented here a successful transition from static to dynamic XES and RIXS to investigate lowspin (LS) $\mathrm{Fe}^{\mathrm{II}}$ complex compounds and their photoinduced spin-transition. The excellent agreement between the results of the different experiments enabled to validate the assumptions previously made for line shape analysis during XES static experiments. In addition, the results demonstrated the power and reliability of using an X-ray spectrometer in combination with ultrafast lasers. With the applied conditions, psresolved resonant hard X-ray spectroscopy has practically reached its full potential at synchrotron radiation sources. These successful pump-probe experiments open up novel exciting opportunities to study many physical, chemical, or biological processes on the ultrafast time scale.

\section{Acknowledgement}

This project was supported by the European Research Council via contract ERC-StG-259709, by the German research community (DFG) via contract SFB925, the European CRISP project, by the European XFEL, and by the Hungarian Scientific Research Fund (OTKA) under contract No. K 72597. A.M.M., G.D., S.H.S., E.P.K., and L.Y. acknowledge support from the U.S. Department of Energy (DOE) Office of Science, Division of Chemical, Geological and Biological Sciences under Contract No. DE- AC02-06CH11357. Use of the Advanced Photon Source, an Office of Science User Facility operated for DOE Office of Science by Argonne National Laboratory, was supported by the U.S. DOE under Contract No. DE-AC02-06CH11357. We acknowledge the assistance of Pablo Fajardo, Christian Hervè, Christophe Lapras, and the staff of ID6 and ID9 from the ESRF as well as the staff of 7-ID from the APS.

\section{References}

[1] A. Hauser, Intersystem crossing in the $\left[\mathrm{Fe}(\mathrm{ptz})_{6}\right]\left(\mathrm{BF}_{4}\right)_{2}$ spin crossover system $(\mathrm{ptz}=1$ propyltetrazole), J. Chem. Phys. 94 (4) (1991) 2741-2748. doi:10.1063/1.459851.

[2] A. Hauser, A. Vef, P. Adler, Intersystem crossing dynamics in $\mathrm{Fe}(\mathrm{II})$ coordination compounds, J. Chem. Phys. 95 (12) (1991) 8710-8717. doi:10.1063/1.461255. 
[3] C. Brady, J. J. McGarvey, J. K. McCusker, H. Toftlund, D. N. Hendrickson, Time-resolved relaxation studies of spin crossover systems in solution, Spin Crossover in Transition Metal Compounds III 235 (2004) 173-184. doi:10.1007/b96439.

[4] C. Bressler, C. Milne, V.-T. Pham, A. ElNahhas, R. M. van der Veen, W. Gawelda, S. Johnson, P. Beaud, D. Grolimund, M. Kaiser, C. N. Borca, G. Ingold, R. Abela, M. Chergui, Femtosecond XANES Study of the LightInduced Spin Crossover Dynamics in an Iron(II) Complex, Science 323 (5913) (2009) 489-492. arXiv:http://www.sciencemag.org/cgi/reprint/323/5 doi:10.1126/science.1165733.

[5] J. K. McCusker, Femtosecond absorption spectroscopy of transition metal chargetransfer complexes, Accounts of Chemical Research 36 (12) (2003) 876-887. arXiv:http://pubs.acs.org/doi/pdf/10.1021/ar030111 doi:10.1021/ar030111d.

[6] W. Gawelda, A. Cannizzo, V.-T. Pham, F. vanMourik, C. Bressler, M. Chergui, Ultrafast nonadiabatic dynamics of $\left[\mathrm{Fe}^{\mathrm{II}}(\mathrm{bpy})_{3}\right]^{2+}$ in solution, Journal of the American Chemical Society 129 (26) (2007) 8199-8206. doi:10.1021/ja070454x.

[7] W. Gawelda, V. T. Pham, A. E. Nahhas, M. Kaiser, Y. Zaushitsyn, S. L. Johnson, D. Grolimund, R. Abela, A. Hauser, C. Bressler, M. Chergui, Capturing transient electronic and molecular structures in liquids by picosecond x-ray absorption spectroscopy, AIP Conference Proceedings 882 (1) (2007) 31-36. doi:10.1063/1.2644425.

[8] W. Gawelda, V.-T. Pham, M. Benfatto, Y. Zaushitsyn, M. Kaiser, D. Grolimund, S. L. Johnson, R. Abela, A. Hauser, C. Bressler, M. Chergui, Structural determination of a short-lived excited iron(ii) complex by picosecond x-ray absorption spectroscopy, Physical Review Letters 98 (5) (2007) 057401. doi:10.1103/PhysRevLett.98.057401.
[9] P. Glatzel, U. Bergmann, High resolution 1s core hole x-ray spectroscopy in 3d transition metal complexes - electronic and structural information, Coord. Chem. Rev. 249 (2005) 65-95. doi:10.1016/j.ccr.2004.04.011.

[10] F. de Groot, A. Kotani, Core Level Spectroscopy of Solids, Taylor \& Francis, New York, 2008.

[11] L. J. P. Ament, M. van Veenendaal, T. P. Devereaux, J. P. Hill, J. van den Brink, Resonant inelastic x-ray scattering studies of elementary excitations, Rev. Mod. Phys. 83 (2011) 705-767. doi:10.1103/RevModPhys.83.705.

/5913/489.pdf,

[12] J.-P. Rueff, A. Shukla, Inelastic x-ray scattering by electronic excitations under high pressure, Rev. Mod. Phys. 82 (1) (2010) 847-896. doi:10.1103/RevModPhys.82.847.

[13] C. Brouder, Angular dependence of x-ray ab,sorption spectra, J. Phys.: Condens. Matter 2 (3) (1990) 701-738. doi:10.1088/0953$8984 / 2 / 3 / 018$.

[14] F. de Groot, G. Vankó, P. Glatzel, The 1s x-ray absorption pre-edge structures in transition metal oxides, Journal of Physics: Condensed Matter 21 (10) (2009) 104207 (7pp).

URL http: //stacks . iop.org/0953-8984/21/104207

[15] D. Cabaret, A. Bordage, A. Juhin, M. Arfaoui, E. Gaudry, First-principles calculations of x-ray absorption spectra at the k-edge of $3 \mathrm{~d}$ transition metals: an electronic structure analysis of the pre-edge, Phys. Chem. Chem. Phys. 12 (2010) 5619-5633. doi:10.1039/B926499J.

[16] J. Yano, V. Yachandra, X-ray absorption spectroscopy, Photosynthesis Research 102 (2) (2009) 241-254. doi:10.1007/s11120-009-9473-8.

[17] U. Bergmann, P. Glatzel, F. de Groot, S. Cramer, High resolution k capture x-ray fluorescence spectroscopy:a new tool for chemicla characterization, J. Am. Chem. Soc. 121 (1999) 4926-4927. 
[18] G. Vankó, T. Neisius, G. Molnár, F. Renz, S. Kárpáti, A. Shukla, F. M. F. de Groot, Molecular spin transitions studied with x-ray emission spectroscopy, J. Phys. Chem. B 110 (2006) 11647-11653. doi:10.1021/jp0615961.

[19] G. Smolentsev, A. V. Soldatov, J. Messinger, K. Merz, T. Weyhermu??ller, U. Bergmann, Y. Pushkar, J. Yano, V. K. Yachandra, P. Glatzel, X-ray emission spectroscopy to study ligand valence orbitals in $\mathrm{mn}$ coordination complexes, Journal of the American Chemical Society 131 (36) (2009) 13161-13167. doi:10.1021/ja808526m.

[20] N. Lee, T. Petrenko, U. Bergmann, F. Neese, S. DeBeer, Probing valence orbital composition with iron $\mathrm{K} \beta \mathrm{x}$-ray emission spectroscopy, Journal of the American Chemical Society 132 (2010) 9715-9727. doi:doi: 10.1021/ja101281e.

[21] R. Alonso Mori, E. Paris, G. Giuli, S. G. Eeckhout, M. Kavcic, M. Zitnik, K. Bucar, L. G. M. Pettersson, P. Glatzel, Sulfurmetal orbital hybridization in sulfur-bearing compounds studied by x-ray emission spectroscopy, Inorganic Chemistry 49 (2010) 6468 6473. doi:10.1021/ic100304z.

[22] J. Swarbrick, Y. Kvashnin, K. Schulte, K. Seenivasan, C. Lamberti, P. Glatzel, Ligand identification in titanium complexes using x-ray valence-to-core emission spectroscopy, Inorganic Chemistry 49 (2010) 8323-8332. doi:10.1021/ic100755t.

[23] M. A. Beckwith, M. Roemelt, M.-N. Collomb, C. DuBoc, T.-C. Weng, U. Bergmann, P. Glatzel, F. Neese, S. DeBeer, Manganese $\mathrm{K} \beta$ x-ray emission spectroscopy as a probe of metal-ligand interactions, Inorganic Chemistry 50 (17) (2011) 8397?-8409. arXiv:http://pubs.acs.org/doi/pdf/10.1021/ic200970t, doi:10.1021/ic200970t.

[24] C. Bressler, M. Chergui, Ultrafast X-ray Absorption Spectroscopy, Chemical Reviews 104 (4) (2004) 1781-1812. doi:NA.
[25] L. X. Chen, Taking snapshots of photoexcited molecules in disordered media by using pulsed synchrotron x-rays, Angewandte Chemie International Edition 43 (22) (2004) 2886-2905. doi:10.1002/anie.200300596.

[26] M. Chergui, Picosecond and femtosecond X-ray absorption spectroscopy of molecular systems, Acta Crystallographica Section A 66 (2) (2010) 229-239. doi:10.1107/S010876730904968X.

[27] M. Christensen, K. Haldrup, K. Bechgaard, R. Feidenhans'l, Q. Kong, M. Cammarata, M. L. Russo, M. Wulff, N. Harrit, M. M. Nielsen, Time-resolved x-ray scattering of an electronically excited state in solution. structure of the ${ }^{3} \mathrm{~A}_{2 u}$ state of tetrakis- $\mu$ pyrophosphitodiplatinate(ii), Journal of the American Chemical Society 131 (2009) 502-508. doi:10.1021/ja804485d.

[28] K. Haldrup, M. Christensen, M. Cammarata, Q. Kong, M. Wulff, S. O. Mariager, K. Bechgaard, R. Feidenhans'l, N. Harrit, M. M. Nielsen, Structural tracking of a bimolecular reaction in solution by time-resolved x-ray scattering, Angewandte Chemie Int. Edition 48 (2009) 41804184 .

[29] M. Lorenc, J. Hébert, N. Moisan, E. Trzop, M. Servol, M. Buron-Le Cointe, H. Cailleau, M. L. Boillot, E. Pontecorvo, M. Wulff, S. Koshihara, E. Collet, Successive dynamical steps of photoinduced switching of a molecular fe(iii) spin-crossover material by time-resolved x-ray diffraction, Phys. Rev. Lett. 103 (2) (2009) 028301. doi:10.1103/PhysRevLett.103.028301.

[30] H. Cailleau, M. Lorenc, L. Guérin, M. Servol, E. Collet, M. Buron-Le Cointe, Structural dynamics of photoinduced molecular switching in the solid state, Acta Crystallographica Section A 66 (2) (2010) 189-197. doi:10.1107/S0108767309051046.

[31] P. Coppens, Molecular excited-state structure by time-resolved pump?probe x-ray diffraction. what is new and what are the prospects 
for further progress?, The Journal of Physical Chemistry Letters 2 (6) (2011) 616-621. arXiv:http://pubs.acs.org/doi/pdf/10.1021/jz200050x doi:10.1021/jz200050x.

[32] M. Chergui, A. H. Zewail, Electron and x-ray methods of ultrafast structural dynamics: Advances and applications, ChemPhysChem 10 (1) (2009) 28-43. doi:10.1002/cphc.200800667.

[33] G. Vankó, P. Glatzel, V.-T. Pham, R. Abela, D. Grolimund, C. N. Borca, S. L. Johnson, C. J. Milne, C. Bressler, Picosecond time-resolved xray emission spectroscopy: Ultrafast spin-state determination in an iron complex, Angewandte Chemie International Edition 49 (34) (2010) 5910-5912. doi:10.1002/anie.201000844.

[34] E. M. Dufresne, B. Adams, D. A. Arms, M. Chollet, E. C. Landahl, Y. Li, D. A. Walko, J. Wang, Time-resolved research at the advanced photon source beamline 7-id, AIP Conference Proceedings 1234 (1) (2010) 181-184. doi:10.1063/1.3463168.

[35] A. M. March, A. Stickrath, G. Doumy, E. P. Kanter, B. Krässig, S. H. Southworth, K. Attenkofer, C. A. Kurtz, L. X. Chen, L. Young, Development of high-repetition-rate laser pump/xray probe methodologies for synchrotron facilities, Rev. Sci. Instrum. 82 (7) (2011) 073110. doi:DOI:10.1063/1.3615245.

[36] W. Gawelda, C. Bressler, M. Saes, M. Kaiser, A. Tarnovsky, D. Grolimund, S. Johnson, R. Abela, M. Chergui, Picosecond time-resolved x-ray absorption spectroscopy of solvated organomettalic complexes, Physica Scripta T115 (2005) 102.

[37] P. Gütlich, A. Hauser, H. Spiering, Thermal and optical switching of iron(ii) complexes, Angew. Chem. Int. Ed. Engl. 33 (20) (1994) 2024-2054. doi:10.1002/anie.199420241.

[38] J. Badro, G. Fiquet, F. Guyot, J.-P. Rueff, V. V. Struzhkin, G. Vankó, G. Monaco, Iron partitioning in the earth's lower mantle; toward a deep lower-mantle discontinuity, Science 300 (2003) 789-791. doi:10.1126/science.1081311.

[39] J.-P. Rueff, C.-C. Kao, V. V. Struzhkin, J. Badro, J. Shu, R. J. Hemley, H. K. Mao, Pressure induced high-spin to low-spin transition in $\mathrm{FeS}$ evidenced by $\mathrm{x}$-ray emission spectroscopy, Phys. Rev. Lett. 82 (1999) 3284-3287. doi:10.1103/PhysRevLett.82.3284.

[40] J.-F. Lin, V. V. Struzhkin, S. D. Jacobsen, M. Y. Hu, P. Chow, J. Kung, H. Liu, H.k. Mao, R. J. Hemley, Spin transition of iron in magnesiowustite in the earth's lower mantle, Nature 436 (7049) (2005) 377-380. doi:10.1038/nature03825.

[41] A. Küçükönder, Y. Şahin, E. Büyükkasap, A. Kopya, Chemical effects on $\mathrm{K} \beta / \mathrm{K} \alpha$ X-ray intensity ratios in coordination compounds of some 3d elements, Journal of Physics B: Atomic, Molecular and Optical Physics 26 (1) (1993) 101.

[42] M. Sikora, K. Knizek, C. Kapusta, P. Glatzel, Evolution of charge and spin state of transition metals in the lamn[sub $1-\mathrm{x}] \operatorname{co}[\mathrm{sub} \mathrm{x}] \mathrm{o}[\mathrm{sub}$ 3] perovskite series, Journal of Applied Physics 103 (7) (2008) 07C907. doi:10.1063/1.2834249.

[43] H. Yamaoka, N. Tsujii, H. Oohashi, D. Nomoto, I. Jarrige, K. Takahiro, K. Ozaki, K. Kawatsura, Y. Takahashi, Bulk electronic properties of $\mathrm{FeSi}_{1-x} \mathrm{Ge}_{x}$ investigated by highresolution $\mathrm{x}$-ray spectroscopies, Physical Review B (Condensed Matter and Materials Physics) $77 \quad$ (11) (2008) 115201. doi:10.1103/PhysRevB.77.115201.

[44] J. Herrero-Martín, A. Mirone, J. FernándezRodríguez, P. Glatzel, J. García, J. Blasco, J. Geck, Hard x-ray probe to study doping-dependent electron redistribution and strong covalency in $\mathrm{La}_{1-\mathrm{x}} \mathrm{Sr}_{1+\mathrm{x}} \mathrm{MnO}_{4}$, Phys. Rev. B 82 (7) (2010) 075112. doi:10.1103/PhysRevB.82.075112.

[45] Z. Mao, J. F. Lin, C. Jacobs, H. C. Watson, Y. Xiao, P. Chow, E. E. Alp, V. B. Prakapenka, 
Electronic spin and valence states of fe in cairo3type silicate post-perovskite in the earth's lowermost mantle, Geophys. Res. Lett. 37 (22) (2010) L22304. doi:10.1029/2010GL045021.

[46] J. P. Rueff, A. Shukla, A. Kaprolat, M. Krisch, M. Lorenzen, F. Sette, R. Verbeni, Magnetism of invar alloys under pressure examined by inelastic x-ray scattering, Phys. Rev. B 63 (13) (2001) 132409. doi:10.1103/PhysRevB.63.132409.

[47] T. E. Westre, P. Kennepohl, J. G. DeWitt, B. Hedman, K. O. Hodgson, E. I. Solomon, A multiplet analysis of Fe K-edge 1s $\rightarrow 3 \mathrm{~d}$ preedge features of iron complexes, J. Am. Chem. Soc. 119 (1997) 6297-6314. 
LS

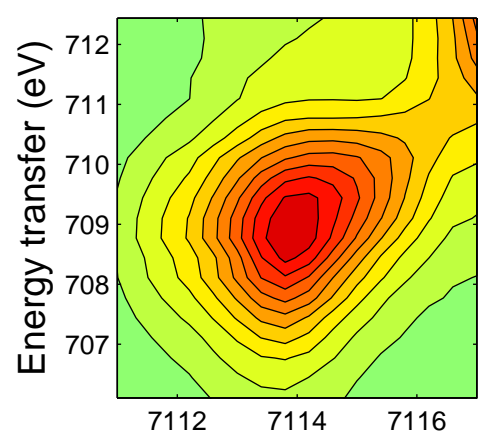

Laser OFF (LS)

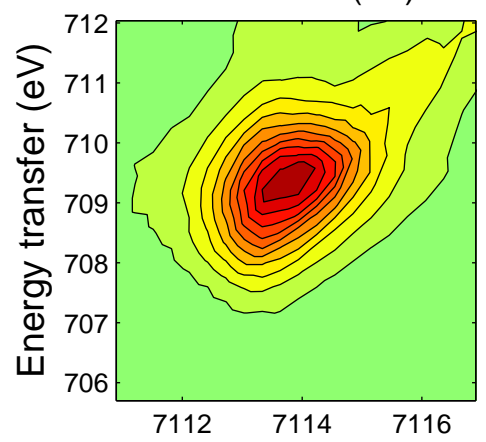

HS

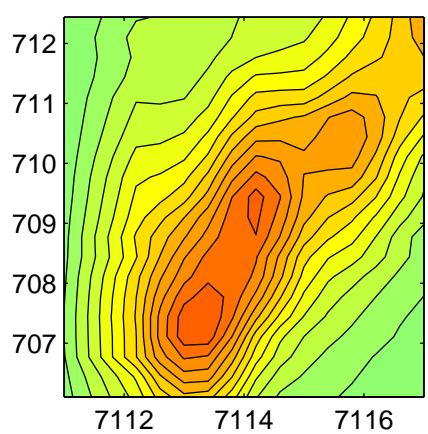

Laser ON (40\% HS)

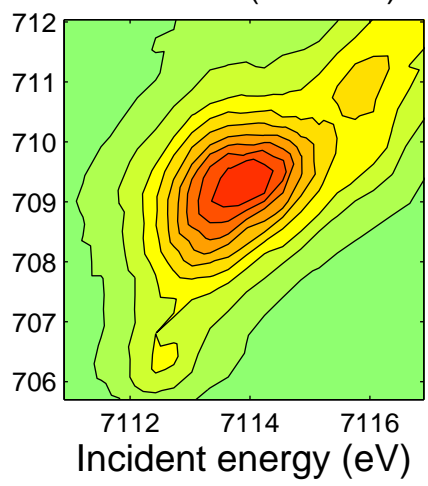

HS-LS

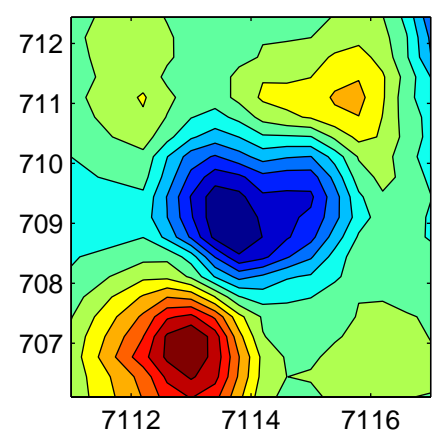

Laser ON-OFF

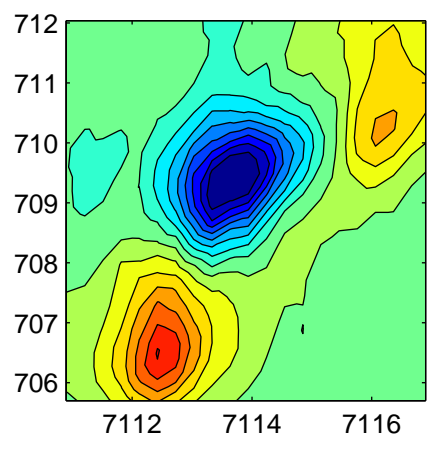

Figure 3: $1 \mathrm{~s} 2 \mathrm{p} * 3 / 2$ RIXS of $\left[\mathrm{Fe}(\mathrm{phen})_{2}(\mathrm{NCS})_{2}\right]$ at thermal spin crossover (upper row), and $\left[\mathrm{Fe}(\text { terpy })_{2}\right]^{2+}$ in aqueous solution at laser excitation (lower row). 